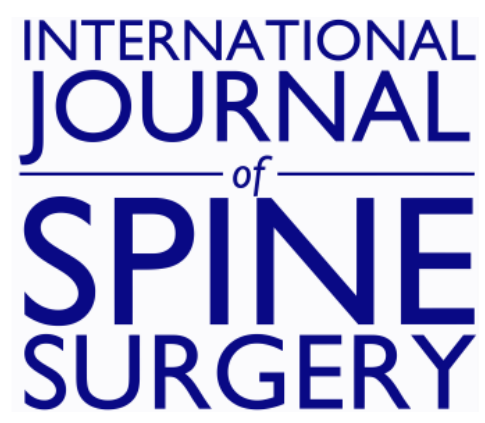

\title{
Suitability of Administrative Databases for Durotomy Incidence Assessment: Comparison to the Incidence Associated With Bone-Removal Devices, Calculated Using a Systemic Literature Review and Clinical Data
}

ROBERT PFLUGMACHER, ANGELO FRANZINI, SHAKED HOROVITZ, RICHARD GUYER and ELY ASHKENAZI

Int J Spine Surg 2018, 12 (4) 498-509

doi: https://doi.org/10.14444/5061

http://ijssurgery.com/content/12/4/498

This information is current as of April 26, 2023.

Email Alerts Receive free email-alerts when new articles cite this article. Sign up at: http://ijssurgery.com/alerts 


\title{
Suitability of Administrative Databases for Durotomy Incidence Assessment: Comparison to the Incidence Associated With Bone-Removal Devices, Calculated Using a Systemic Literature Review and Clinical Data
}

\author{
ROBERT PFLUGMACHER, MD, ${ }^{1}$ ANGELO FRANZINI, MD ${ }^{2}$ SHAKED HOROVITZ, ${ }^{3}$ RICHARD GUYER, \\ MD, ${ }^{4}$ ELY ASHKENAZI, MD ${ }^{5}$ \\ ${ }^{1}$ Klinik und Poliklinik Für Orthopädie und Unfallchirurgie, Universitätsklinikum Bonn, Bonn, Germany, ${ }^{2}$ Department of Neurosurgery, Fondazione Istituto \\ Neurologico "Carlo Besta," Milan, Italy, ${ }^{3}$ Carevature Medical, Ltd, Rehovot, Israel, ${ }^{4}$ Texas Back Institute, Plano, Texas, ${ }^{5}$ Israel Spine Center, Assuta Medical \\ Center, Tel Aviv, Israel
}

\begin{abstract}
Background: Durotomy is a major complication of spinal surgery, potentially leading to additional clinical complications, longer hospitalization, and increased costs. A reference durotomy incidence rate is useful for the evaluation of the safety of different surgical aspects. However, the literature offers a wide range of incidence rates, complicating this comparison. Theoretically, a reference incidence value can be extracted from administrative databases, containing a large number of procedures. However, it is suspected that these databases suffer from underreporting of complications. This study aims to evaluate durotomy incidence using several large-scale databases and to assess the ability to use it as a reference by comparison to durotomy incidences directly associated with 4 bone removal devices, including the commonly used high-speed drill.

Methods: Durotomy overall incidence was estimated from several administrative databases using different methods in order to achieve minimal and maximal estimations. Durotomy incidences for 3 bone removal devices were derived using literature meta-analysis, and the incidence for the fourth device was calculated using clinical data.

Results: The incidence range of durotomy according to the databases was $2.8-3.5 \%$. The calculated incidence of durotomy for the studied devices was $0.4-2.91 \%$. The highest rate, $2.91 \%$, is associated with the commonly used highspeed drill combined with Kerrison Rongeur and bone punches. Since bone-removal devices are just one of the possible causes of dural tears, the general incidence is expected to be higher than the incidence associated with the devices, yet even the maximal estimation, $3.5 \%$, was only slightly higher, suggesting that the speculation of underreporting of dural tears to these databases is probably true, as also supported by the mostly higher incidences reported in the literature.

Conclusions: Hospital administrative databases seem to show a lower-than-reasonable incidence of durotomy, suggesting possible underreporting. Researchers should therefore use this tool with caution. Reduction of the absolute durotomy incidence by approximately $2.5 \%$ can be achieved by improving the safety of bone-removal devices.
\end{abstract}

Complications

Keywords: incidental dural tears, durotomy, tissue-removal devices, high-speed drill

\section{INTRODUCTION}

The dura mater encloses the brain, spinal cord, cauda equina, nerve roots, and cerebrospinal fluid (CSF). A durotomy, or dural tear, can occur during spinal surgery, requiring a water-tight dural closure in order to prevent a CSF leak. Without adequate treatment, CSF leak can lead to clinical complications such as pseudomeningocele, meningitis, and re-operation. ${ }^{1-3}$ In addition, durotomy often leads to longer hospitalization and increased costs. ${ }^{4,5}$
A reference durotomy incidence rate is useful for evaluating the safety of different surgical aspects, such as surgical devices and alternatives. However, the overall incidence of dural tears varies between different studies, from 0.5 to over $16 \%,,^{3,6-10}$ and in some studies even as high as $40 \%{ }^{11}$ This wide variation is a result of many factors, such as the number of cases reviewed, patient age, sex and medical record, the complexity of the procedures performed, surgeon experience, and the number of institutions surveyed. ${ }^{4,8,10,12,13}$ Large-scale administrative databases, which include a very large number 
of hospitalization records, hold a great potential for incidence analysis of various medical conditions, due to their size, diversity, and relatively low cost to the researcher. More specifically, they may assist in determining a more accurate reference incidence rate for durotomy.

Two studies in the past examined such large-scale databases (including 108478 and 665818 patients) and reported durotomy incidences of 1.6 and $2.7 \%$, respectively. ${ }^{14,15}$ Unfortunately, administrative databases may be prone to underreporting of complication rates, comorbidities, performed tests, and mortality rates. ${ }^{16-21}$ Potential explanations include inconsistencies in definitions, coding and documentation, and lack of reporting on the medical record by the attending physician, ${ }^{19,21}$ as well as lacking training and knowledge of the administrative database personnel and their reduced involvement in the entire hospitalization process. ${ }^{22}$

In addition, database durotomy incidence may be lower than the actual incidence since, unfortunately, up to $10 \%$ of the dural tears are not detected during surgery and may be diagnosed even 5 days later. ${ }^{6,23}$ Therefore, studies ${ }^{15}$ that calculate the incidence of dural tears diagnosed during the same hospitalization as the surgery may be underestimating the incidence of this complication. This issue can potentially be addressed by using all the reported durotomies in a database for the calculation.

Due to these potential drawbacks and the importance of this complication, it is therefore uncertain that administrative databases can be used to calculate the overall incidence of dural tears. Since these databases are an accessible tool, which can be easily analyzed, it is important to verify that they are indeed suitable for this purpose, yet their appropriateness for this calculation was not evaluated in the past.

This study aims to evaluate durotomy incidence from several large-scale databases using different assumptions in order to extract a possible reference range. In order to assess the chance of underreporting to these databases and their suitability for this type of analysis, the results were then compared to durotomy incidences associated with several boneremoval devices used in spinal surgeries. These devices can potentially cause dural tears and are therefore an important factor affecting the overall incidence. However, since they are not the only possible cause of tears, it is expected that the durotomy incidence directly associated with a

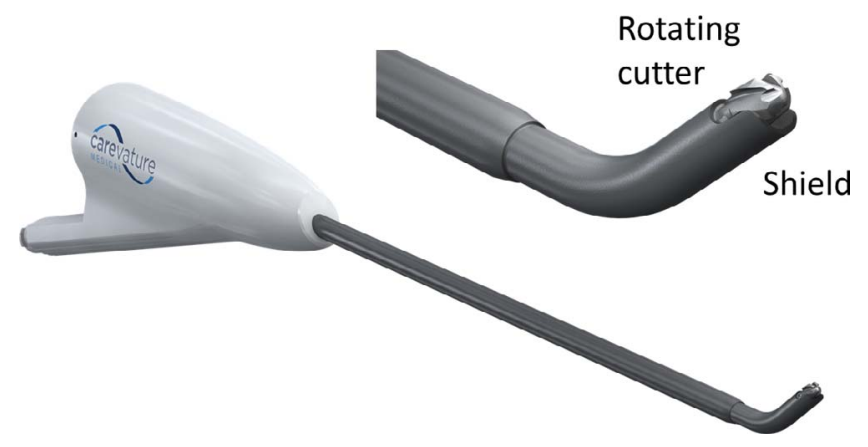

Figure 1. Lower left: The DReal Decompression System. Upper right: Expanded view of the distal tip.

specific device will be lower than the general overall incidence, which includes all potential causes. By isolating the incidence associated with bone-removal devices, it is also possible to estimate the potential complication rate reduction that can be obtained by improving the safety of these devices.

The incidences directly associated with 4 boneremoval devices were calculated using a systematic review of the existing literature and recent clinical data. Four device types were investigated: Highspeed drills (HSDs), ultrasonic BoneScalpel (UBS; Misonix Inc, Farmingdale, New York), Sonopet Ultrasonic Aspirator (SUA; Miwatec Co, Ltd, Tokyo, Japan), and the DReal Decompression System (DDS; Carevature Medical Ltd, Rehovot, Israel).

The UBS, SUA, and DDS are designed to increase procedure safety and reduce the chances of durotomy associated with the commonly used HSDs. The ultrasonic devices offer localized bone removal by using longitudinal vibrations at high frequencies. The DDS is a high-speed, drill-like bone removal instrument with a curved tip at its distal end, shielded on the underside in order to protect neural elements (Figure 1).

\section{MATERIALS AND METHODS}

\section{Estimating the General Incidence of Durotomy}

The incidence of durotomy in spinal surgeries was calculated using a combination of results from previously published studies ${ }^{14,15}$ in addition to new data extracted from 2 nationwide administrative databases.

The Healthcare Cost and Utilization Project (HCUP) National Inpatient Sample (NIS), maintained by the Agency for Healthcare Research and Quality, ${ }^{24}$ is the largest all-payer database in the United States. This database contains data approx- 
imating a $20 \%$ stratified sample of US hospitals. The most recent available version of the database, for the year 2014, was accessed and used for this study.

The National Hospital Discharge Survey (NHDS), maintained by the Centers for Disease Control and Prevention (CDC), ${ }^{25}$ was a national probability survey that documented the characteristics of inpatients discharged from nonfederal short-stay hospitals in the United States. This database represents over 6 million hospitalizations. The latest available version of this database, for the year 2010, was used for this investigation.

The number of discharges for which the principle procedure conducted was spinal surgery was extracted from both databases. For this purpose, spinal surgery was defined as procedures grouped under HCUP's Clinical Classifications Software categories 3 (decompression procedures, such as laminectomy, and excision of intervertebral disc) and 158 (spinal fusion). Only adult patients were included (age $\geq 18$ years).

The number of discharges with a diagnosis of dural tear was queried from both databases by retrieving the number of discharges with a diagnosis code of "accidental puncture or laceration of dura during a procedure" (International Classification of Diseases, Ninth Revision code 349.31).

\section{Estimating Durotomy Incidence Associated with Bone Removal Devices}

The safety of the HSD, UBS, and SUA was assessed from the literature. Data regarding dural tear incidence were extracted or calculated from previous publications. The Preferred Reporting Items for Systematic Reviews and Meta-Analyses (PRISMA) guidelines ${ }^{26}$ were followed and used to create the review protocol.

The Google Scholar publication database was searched during January 2018 for combinations of the following keywords: "durotomy" or "dural tear" with either "ultrasonic bone scalpel," "ultrasonic bone curette," "BoneScalpel," "Sonopet," "ultrasonic osteotome," "high speed burr," or "high speed drill." The search was limited to publications in English and was not limited by publication date. The results were reviewed, and publications were selected for further review if they described spinal procedures performed using the devices. Publications referenced by these studies which seemed relevant to this research were also added to the review. In order to be included, publications had to include the number of patients and the number of dural tears, as well as to indicate whether the device in question was used for all the procedures and whether it was the cause of the dural tear.

Studies defined as retrospective or studies that are retrospective in nature (for example, based on records 5 years prior to the publication) were excluded from the HSD analysis due to 2 reasons: First, hospital databases may suffer from underreporting due to the same reasons as the national databases and therefore do not serve the purpose of this comparison. Second, since the cause of the tear was required for the inclusion in the analysis, all studies that reported on a non- 0 incidence, without cause description, had to be excluded. However, there were several studies reporting a $0 \%$ dural tear incidence, which had to be included since the cause of tear was irrelevant. This created a bias, favoring studies with the unrealistic $0 \%$ incidence, while studies with more reasonable or even high incidences had to be excluded.

Retrospective studies were included in the analysis of the other devices since it was assumed that all studies discussing the use of new devices would specifically focus on adverse events and would therefore not suffer from underreporting and would also include a sufficient description of the causes of the tears, avoiding the 0-incidence bias (and indeed all the USB and SUA studies included a statement regarding device-related tears). In addition, since newer devices, designed for a safer procedure, are expected to have lower incidences and were usually used in less procedures, it was decided to include all relevant studies in order to improve the accuracy of the meta-analysis. The different inclusion rule between the HSD and the other devices is not ideal, but it was assumed that the alternative would be more biased.

Publications were also excluded if they described case reports (3 procedures or less), literature reviews, or procedures on pediatric patients or patients suffering from severe pathologies. The pathologies excluded were achondroplasia, spinal deformities, dural defects or lesions (such as dural herniation or tumors), spinal fractures, cranial procedures, and patients with an ossification of the ligamentum flavum. The motivation for these exclusions is the relatively higher rate of dural tears in these cases, which in some cases exceeded $30 \%$. 
These exclusion criteria were set in order to reduce the risk of bias due to the use of studies performed on uncharacteristic population or methods. The studies were scanned for information regarding the number of participants, the procedures performed, relevant devices, the number of dural tears, and their causes. For the UBS and SUA, only tears associated with the specific devices were used for the incidence calculation. For the HSD, it has been suggested in the literature that the incidence calculation should include tears caused by the Kerrison Rongeur (KR) and bone punches (BP) as well. As mentioned in one of the studies: "In all cases of dural tears using the [HSD], the actual tearing mechanism was due to the Kerrison punch. We continue to classify these cases under the [HSD] category as the use of the drill necessitates extensive use of the Kerrison punch as well." ${ }^{27}$ The use of the UBS, SUA, and DDS reduces the need to use the KR or BP since their function can be performed using these devices. In addition, many UBS and SUA studies do not report the KR/BP-related tears. Due to both reasons, the UBS and SUA analysis included only device-related tears and not KR/BP tears. The incidence associated with the HSD alone, without the $\mathrm{KR}$ or BP, was also calculated and reported in order to facilitate a broader comparison. The risk of bias of each study was evaluated using the Cochrane Collaboration's tool for assessing risk of bias. ${ }^{28}$

The dural tear incidence of the DDS was calculated using clinical data acquired during 502 surgical cases performed between February 2013 and January 2018. Although the device was used for a total of 646 procedures, this analysis includes only the surgical procedures for which reliable reports on potential adverse events were available. No tears were reported for any of the procedures not included in this analysis. These cases comprise a wide variety of procedures, surgeons, and geographical locations, as described in Table 1. All patients gave their informed consent to conducting these procedures. The experimental protocol and informed consent were approved by the Institutional Review Board. The incidence of durotomy was calculated using the number of dural tears associated with the use of this device. The risk of bias of this study was assessed as well. ${ }^{28}$

\section{Calculating the Durotomy Incidence Associated with the Bone-Removal Devices}

The integrated durotomy incidence was calculated for each device using a meta-analysis feature of
Table 1. Summary of reviewed DReal Decompression System cases.

\begin{tabular}{lr}
\hline Countries & 7 \\
Hospitals & 34 \\
Surgeons & 48 \\
Procedures & 18 \\
Lumbar TLIF (open) & 173 \\
Lumbar TLIF (MIS) & 6 \\
Lumbar PLIF & 11 \\
Lumbar tumor & 4 \\
OLIF & 2 \\
ALIF & 2 \\
Lumbar decompression (open) & 148 \\
Lumbar decompression (MIS) & 72 \\
Thoracic TLIF & 11 \\
Thoracic decompression & 2 \\
ACDF & 19 \\
Cervical corpectomy & 30 \\
Cervical tumor removal & 1 \\
Cervical uncusectomy & 12 \\
Cervical decompression & 3 \\
Cervical osteophyte removal & 2 \\
Posterior cervical decompression & 2 \\
Total reviewed cases & 502 \\
\end{tabular}

Abbreviations: DDS, DReal Decompression System; ACDF, anterior cervical discectomy and fusion; ALIF, anterior lumbar interbody fusion; MIS, minimally invasive surgery; OLIF, oblique lumbar interbody fusion; PLIF, posterior lumbar interbody fusion; TLIF, transforaminal lumbar interbody fusion.

the statistical software JASP (version 0.8.1.0, The JASP team, 2017) using the restricted maximumlikelihood (REML) random effects model. Since the incidences are equal or close to 0 , a normal distribution cannot be assumed. Therefore, the Freeman-Tukey double arcsine transformation was used for the calculation, and the inverse transformation was used to interpret the results. ${ }^{29,30}$

The calculated incidences were compared to the general incidence and to the incidences calculated for other devices. The significance of the device group separation was evaluated using a Student's $t$ test and a value of $P<.05$ was considered as statistically significant.

The heterogeneity of each subgroup was evaluated qualitatively using forest plots and quantitatively by the $I^{2}$ value $^{31}$ calculated by the statistical software.

Ninety-five percent confidence levels for the DDS were calculated using a binomial confidence interval calculator. $^{32,33}$

\section{RESULTS}

\section{Overall Incidence of Dural Tears}

The total number of hospitalizations due to spinal surgery in the 2014 NIS database was $566321 ; 151710(26.8 \%)$ of these procedures were decompression and disc excision procedures, and $414611(73.2 \%)$ were spinal fusions. The total 


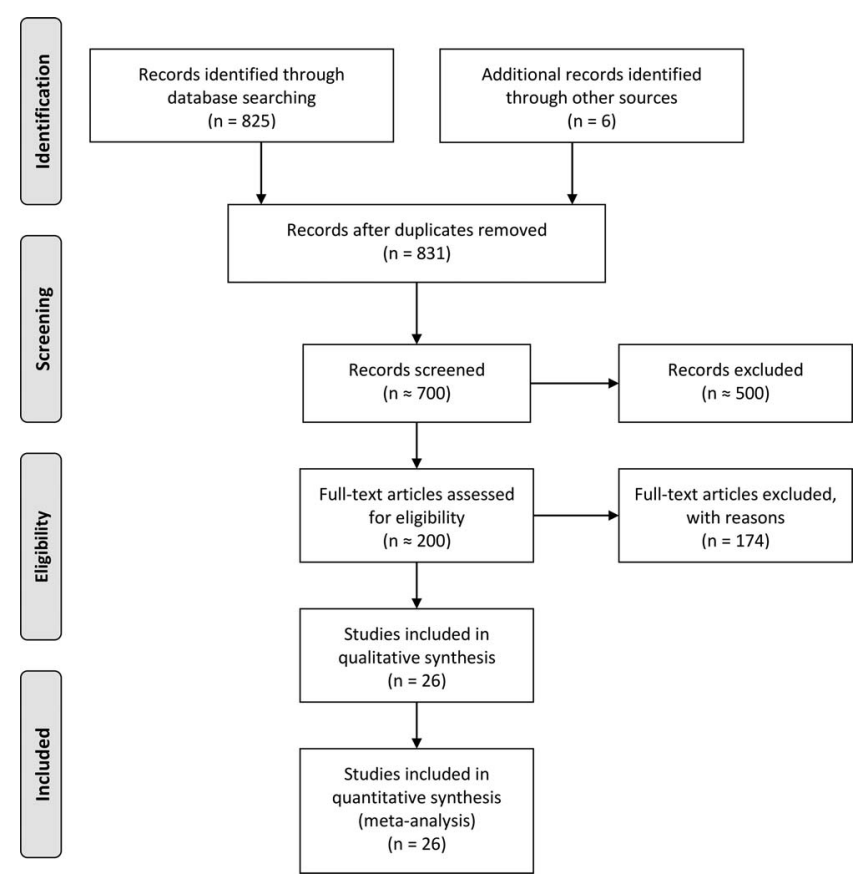

Figure 2. Preferred Reporting Items for Systematic Reviews and MetaAnalyses flow chart of the studies assessed for the systematic literature review.

number of hospitalizations with dural tears was 19820. The calculated incidence is therefore $3.5 \%$.

The total number of hospitalizations due to spinal surgery in the 2010 NHDS database was 449101 (74.3\% fusions, $24.3 \%$ decompressions and disc excisions, and $1.4 \%$ other procedures). The procedure distribution is similar in both databases, suggesting that any differences in the dural tear incidence are not a result of different procedures. The total number of hospitalizations with a dural tear diagnosis was 15354, and the calculated incidence is therefore $3.4 \%$. The incidence of durotomy diagnosed and reported during the same hospitalization in which a spinal surgery was performed was lower: 2.8\% (12905 cases), suggesting that $84 \%$ of the tears are diagnosed and fully repaired during the original hospitalization.

In order to compare results between the databases and verify that any changes are not a result of technological progression or technique changes, the NIS 2010 database was also compared with the NHDS database. Using the same calculation method, the dural tear rate in the 2010 NIS was $3.24 \%$, compared with $3.5 \%$ in 2014 . This seems to be within a reasonable range of error and not the result of an ongoing trend (in comparison, the 2011 rate was $3.45 \%$ followed by $3.34 \%$ for 2012 and $3.44 \%$ for 2013). These results show that both databases report a similar overall incidence and therefore can be compared, despite the time difference.

The type of surgery is also one of the factors affecting the dural tear rate. For example, studies on the NIS database from approximately the same time $\mathrm{e}^{4,15,34,35}$ found that the dural tear rate for disc herniations was $1.9 \%$, compared with $6.3 \%$ for decompressions, $4.7 \%$ for short fusions, and $0.4 \%$ for cervical surgeries. According to the NHDS data, $2.1 \%$ of fusion surgeries resulted in an incidental durotomy. The rate for nonfusion procedures is not reported here since the number of unweighted records is too low to be considered accurate according to the NHDS documentation.

As these calculations show, the estimated incidence varies between databases and was affected by the assumption that the dural tear is diagnosed at the same hospitalization as the surgery. The NIS and NHDS databases show similar results and procedure distributions. The range of durotomy incidence, based on these large-scale databases, is therefore $2.8-3.5 \%$, depending on the method and database used.

\section{Dural Tears Associated with Bone-Removal Devices}

Overall, the different search keywords retrieved 825 publications. Six additional publications were added from relevant citations by other studies. As the flowchart on Figure 2 shows, these studies were scanned for relevance, and after applying the exclusion criteria, 26 publications were found suitable for the quantitative analysis and are described in this study. ${ }^{27,36-60}$

The different studies included, their results, and risk of bias assessment are described in Tables 2 and 3.

Some of the studies are inherently biased. For example, blinding of the surgeon to the device used is not possible. In addition, patient selection is usually biased in nonrandomized trials since the surgeon may choose specific procedures and conditions that are more suitable for the new device. New devices may cause more tears during an initial learning period, which is usually included in the reported studies due to the relatively low number of available cases. However, since this study aims to compare the different devices under a similar setting, these differences are acceptable since they affect all new devices in a similar way. 
Table 2. Publications used for the device durotomy incidence analysis.

\begin{tabular}{|c|c|c|c|c|c|c|c|}
\hline \multirow[b]{2}{*}{ Study } & \multirow[b]{2}{*}{ Patient No. } & \multirow{2}{*}{$\begin{array}{l}\text { Overall } \\
\text { Dural } \\
\text { Tears }\end{array}$} & \multicolumn{4}{|c|}{$\begin{array}{l}\text { Dural Tears } \\
\text { Associated with the Device }\end{array}$} & \multirow[b]{2}{*}{ Procedure } \\
\hline & & & HSD & SUA & $\mathbf{K R} / \mathbf{B P}$ & UBS & \\
\hline Al-Mahfoudh et $\mathrm{al}^{36}$ & 62 & 4 & NA & NA & 3 & 1 & Spinal surgery cases \\
\hline \multirow[t]{2}{*}{ Bydon et $\mathrm{al}^{27}$} & 249 & 9 & 0 & NA & 9 & NA & Posterior cervical or thoracic decompression \\
\hline & 88 & 5 & NA & NA & 0 & 5 & $\begin{array}{l}\text { with or without instrumented fusion for } \\
\text { extradural pathologies. }\end{array}$ \\
\hline Choi et $\mathrm{al}^{37}$ & 21 & 1 & 0 & NA & 1 & NA & $\begin{array}{l}\text { Minimally invasive spinal transforaminal } \\
\text { lumbar interbody fusion }\end{array}$ \\
\hline Dezawa et $\mathrm{al}^{38}$ & 9 & 0 & 0 & NA & 0 & NA & $\begin{array}{l}\text { Percutaneous endoscopic discectomy for hidden- } \\
\text { zone herniated nucleus pulposus }\end{array}$ \\
\hline Eldin et $\mathrm{al}^{50}$ & 28 & 0 & 0 & NA & 0 & NA & $\begin{array}{l}\text { Mini-open transforaminal lumbar interbody } \\
\text { fusion combined with transpedicular screw } \\
\text { fixation for spondylolisthesis and } \\
\text { degenerative disc disease }\end{array}$ \\
\hline Farooq et $\mathrm{al}^{40}$ & 200 & 14 & 4 & NA & 5 & NA & Lumbar spine surgery \\
\hline Hazer et $\mathrm{al}^{39}$ & 307 & 5 & NA & NA & NA & 5 & Various \\
\hline Hu et $\mathrm{al}^{41}$ & 128 & 11 & NA & NA & NA & 2 & Various \\
\hline Hiraizumi $^{51}$ & 50 & 4 & 1 & NA & 1 & NA & Endoscopic lumbar discectomy, first 50 cases \\
\hline Ito et $\mathrm{al}^{42}$ & 12 & 1 & NA & 1 & NA & NA & $\begin{array}{l}\text { Laminoplastic laminotomy and } \\
\text { hemilaminotomy }\end{array}$ \\
\hline Kast et $\mathrm{al}^{43}$ & 26 & 1 & 1 & NA & NA & NA & $\begin{array}{l}\text { Cervical, occipitocervical, or cervicothoracic } \\
\text { stabilization }\end{array}$ \\
\hline Kim et $\mathrm{al}^{44}$ & 546 & 5 & 0 & 5 & NA & NA & Various \\
\hline Lidar et $\mathrm{al}^{59}$ & 10 & 0 & 0 & NA & 0 & NA & $\begin{array}{l}\text { Minimally invasive extracavitary approach for } \\
\text { thoracic disc herniation }\end{array}$ \\
\hline \multirow[t]{2}{*}{ Martín-Láen et al ${ }^{60}$} & 101 & 6 & $?$ & NA & $?$ & NA & Conventional microsurgical discectomy \\
\hline & 37 & 2 & 1 & NA & 0 & NA & Microendoscopic discectomy \\
\hline Matsuoka et $\mathrm{al}^{45}$ & 33 & $?$ & NA & 0 & NA & NA & Various \\
\hline Mummaneni et $\mathrm{al}^{52}$ & 32 & 1 & 0 & NA & 1 & NA & Posterior cervical fixation \\
\hline Nakagawa et al ${ }^{46}$ & 76 & $?$ & NA & 0 & NA & NA & Various \\
\hline Nakase et $\mathrm{al}^{47}$ & 98 & $?$ & $?$ & 0 & NA & NA & Various \\
\hline Nomura and Yoshida ${ }^{53}$ & 70 & 0 & 0 & NA & 0 & NA & Microendoscopic spinal decompression \\
\hline \multirow[t]{2}{*}{ Onen et $\mathrm{al}^{54}$} & 23 & 3 & $?$ & NA & $?$ & NA & Posterior laminectomy to treat cervical \\
\hline & 23 & 0 & NA & NA & NA & 0 & spondylotic myelopathy \\
\hline Orpen et $\mathrm{al}^{55}$ & 100 & 1 & 0 & NA & 1 & NA & Micro-decompression of the lumbar spine \\
\hline Pakzaban $^{48}$ & 218 & 4 & NA & NA & NA & 2 & Various \\
\hline Parker et al $^{49}$ & 40 & 1 & NA & NA & NA & 1 & Osteoplastic laminoplasty \\
\hline Siddiqui and Yonemura ${ }^{56}$ & 14 & 0 & 0 & NA & 0 & NA & $\begin{array}{l}\text { Cervical microendoscopic discectomy and } \\
\text { laminoforaminotomy }\end{array}$ \\
\hline Sunder and Prasad ${ }^{57}$ & 40 & 0 & 0 & NA & 0 & NA & Microscopic laminotomy and foraminotomy \\
\hline Velho et $\mathrm{al}^{58}$ & 96 (19 spinal) & 0 & NA & NA & NA & 0 & $\begin{array}{l}\text { Laminectomies (lumbar and cervical) and } \\
\text { cervical corpectomies }\end{array}$ \\
\hline
\end{tabular}

Abbreviations: HSD, high-speed drill; KR/BP, Kerrison Rongeur/bone punch; NA, not applicable; SUA, Sonopet Ultrasonic Aspirator; UBS, ultrasonic BoneScalpel.

Figures 3-5 show the distribution of the incidences calculated using each of the studies used for the HSD, UBS, and SUA evaluations, respectively. The cumulative incidence was calculated by dividing the total number of dural tears by the total number of patients.

For the DDS, the incidence is calculated using the clinical experience described above. Two tears occurred during the 502 procedures in which the device was used, both during lumbar decompressions. The calculated overall incidence is $0.4 \%$. The $95 \%$ confidence level is $[0.05,1.43 \%]$. The risk of bias is unclear for the "random sequence generation" item since some of the surgeons may choose to use the device on more difficult cases, high for the blinding items (as for the other devices) and low for the other items.
Figure 6 shows the calculated incidences for all the devices. The error bars show the $95 \%$ confidence intervals.

The calculated heterogeneity parameters, $I^{2}$, for each device subgroup are shown in Table 4. As the table shows, the heterogeneity is low, suggesting that these studies can be used together for the metaanalysis.

The calculated incidences associated with the HSD with the KR/BP were $4.76,{ }^{37} 4.5,{ }^{40} 4,{ }^{51} 3.85,{ }^{43}$ $3.61,{ }^{27} 3.13,{ }^{52} 2.7,{ }^{60} 1,{ }^{55}$ and $0 \%{ }^{38,50,53,56,57,59}$ (6 studies). The calculated pooled incidence is $2.91 \%$. Although the incidences reported vary, the heterogeneity was low (calculated $I^{2}$ of $11.4 \%$ ), possibly due to the relatively small sample sizes of some of these studies, leading to overlapping confidence intervals. 


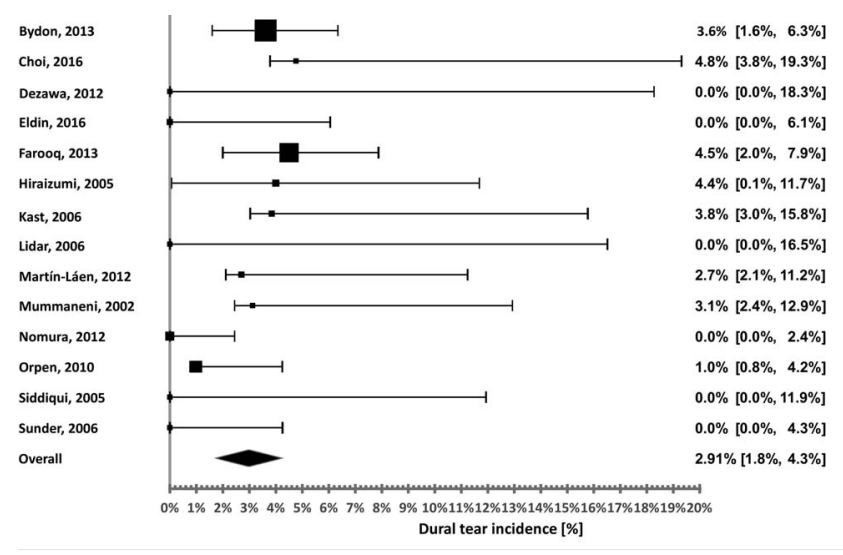

Figure 3. High-speed drill durotomy incidence distribution.

The same analysis was conducted on dural tears associated with the HSD alone, without the KR/BP. There were 3 studies that specified that the tear occurred during bone removal, but not the specific device. The pooled incidence was calculated twice: Assuming all these tears are HSD-related and assuming they were caused by the KR/BP.

According to these calculations, the HSD-related incidence was $0.9-1.3 \%$. These are very low rates, which seem to be unrealistic, as they are as low as the incidences obtained by the devices designed for a safer bone removal or even lower. As mentioned,

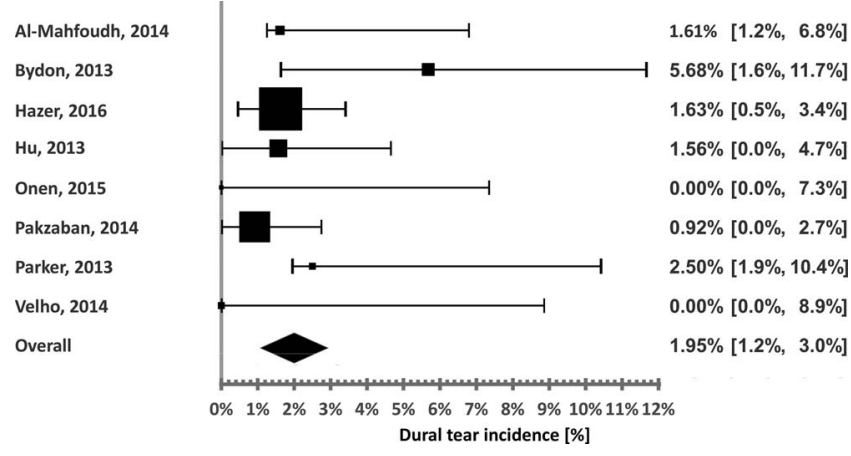

Figure 4. Ultrasonic BoneScalpel durotomy incidence distribution.

these safer devices aim to replace the heavy use of drills with $\mathrm{KR} / \mathrm{BP}$, and therefore the combination is considered here as the overall alternative.

The calculated incidences associated with the UBS were $5.68,{ }^{27} 2.5,{ }^{49} 1.63,{ }^{39} 1.61,{ }^{36} 1.56,{ }^{41} 0.92,{ }^{48}$ and $0 \%{ }^{54,58}$ ( 2 studies). The pooled incidence is $1.95 \%$. The calculated heterogeneity was very low $\left(I^{2}=0 \%\right)$.

The calculated incidences associated with the SUA were $8.3,{ }^{42} 0.92,{ }^{44}$ and $0 \%$ (3 studies) ${ }^{45-47}$ The high-incidence study is significantly smaller than the other studies (12 patients), and therefore its effect on the overall calculated incidence is very small. This is also demonstrated by the very low hetero-

Table 3. Risk of bias for the publications used for the device durotomy incidence analysis.

\begin{tabular}{|c|c|c|c|c|c|c|c|c|}
\hline & $\begin{array}{c}\text { Random } \\
\text { Sequence } \\
\text { Generation }\end{array}$ & $\begin{array}{c}\text { Allocation } \\
\text { Concealment }\end{array}$ & $\begin{array}{c}\text { Blinding of } \\
\text { Participants } \\
\text { and Personnel }\end{array}$ & $\begin{array}{l}\text { Blinding of } \\
\text { Outcome } \\
\text { Assessment }\end{array}$ & $\begin{array}{c}\text { Incomplete } \\
\text { Outcome } \\
\text { Data }\end{array}$ & $\begin{array}{c}\text { Selective } \\
\text { Reporting }\end{array}$ & $\begin{array}{c}\text { Other } \\
\text { Bias }\end{array}$ & Comments \\
\hline Al-Mahfoudh et $\mathrm{al}^{36}$ & $\mathrm{H}$ & $\mathrm{H}$ & $\mathrm{H}$ & $\mathrm{H}$ & $\mathrm{L}$ & $\mathrm{L}$ & $\mathrm{L}$ & \\
\hline Bydon et $\mathrm{al}^{27}$ & $\mathrm{H}$ & $\mathrm{H}$ & $\mathrm{H}$ & $\mathrm{H}$ & $\mathrm{L}$ & $\mathrm{L}$ & $\mathrm{L}$ & \\
\hline Choi et $\mathrm{al}^{37}$ & $\mathrm{~L}$ & $\mathrm{~L}$ & $\mathrm{~L}$ & $\mathrm{~L}$ & $\mathrm{~L}$ & $\mathrm{~L}$ & $\mathrm{H}$ & $\mathrm{C} 1$ \\
\hline Dezawa et $\mathrm{al}^{38}$ & $\bar{L}$ & $\mathrm{~L}$ & $\bar{L}$ & $\mathrm{~L}$ & $\mathrm{~L}$ & $\mathrm{~L}$ & $\mathrm{~L}$ & \\
\hline Eldin et $\mathrm{al}^{50}$ & $\mathrm{~L}$ & $\mathrm{~L}$ & $\mathrm{~L}$ & $\mathrm{~L}$ & $\mathrm{~L}$ & $\mathrm{~L}$ & $\mathrm{~L}$ & \\
\hline Farooq et $\mathrm{al}^{40}$ & $\mathrm{~L}$ & $\mathrm{~L}$ & $\mathrm{~L}$ & $\mathrm{~L}$ & $\mathrm{~L}$ & $\mathrm{~L}$ & $\mathrm{~L}$ & \\
\hline Hazer et $\mathrm{al}^{39}$ & $\mathrm{H}$ & $\mathrm{H}$ & $\mathrm{H}$ & $\mathrm{H}$ & $\mathrm{L}$ & $\mathrm{L}$ & $\mathrm{L}$ & $\mathrm{C} 2$ \\
\hline $\mathrm{Hu}$ et $\mathrm{al}^{41}$ & $\mathrm{H}$ & $\mathrm{H}$ & $\mathrm{H}$ & $\mathrm{H}$ & $\mathrm{L}$ & $\mathrm{L}$ & $\mathrm{L}$ & $\mathrm{C} 2$ \\
\hline Hiraizumi $^{51}$ & $?$ & $\mathrm{~L}$ & $\mathrm{~L}$ & $\mathrm{~L}$ & $\mathrm{~L}$ & $\mathrm{~L}$ & $\mathrm{H}$ & $\mathrm{C} 2$ \\
\hline Ito et $\mathrm{al}^{42}$ & $\mathrm{H}$ & $\mathrm{H}$ & $\mathrm{H}$ & $\mathrm{H}$ & $\mathrm{L}$ & $\mathrm{L}$ & $\mathrm{H}$ & \\
\hline Kast et $\mathrm{al}^{43}$ & $\mathrm{~L}$ & $\mathrm{~L}$ & $\mathrm{~L}$ & $\mathrm{~L}$ & $\mathrm{~L}$ & $\mathrm{~L}$ & $\mathrm{~L}$ & \\
\hline Kim et $\mathrm{al}^{44}$ & $\mathrm{H}$ & $\mathrm{H}$ & $\mathrm{H}$ & $\mathrm{H}$ & $\mathrm{L}$ & $\mathrm{L}$ & $\mathrm{L}$ & \\
\hline Lidar et $\mathrm{al}^{59}$ & $\mathrm{~L}$ & $\mathrm{~L}$ & $\mathrm{~L}$ & $\mathrm{~L}$ & $\mathrm{~L}$ & $\mathrm{~L}$ & $\mathrm{~L}$ & \\
\hline Martín-Láen et al ${ }^{60}$ & $\mathrm{H}$ & $\mathrm{H}$ & $\mathrm{H}$ & $\mathrm{H}$ & $\mathrm{H}$ & $\mathrm{L}$ & $\mathrm{L}$ & $\mathrm{C} 3$ \\
\hline Matsuoka et $\mathrm{al}^{45}$ & $\mathrm{H}$ & $\mathrm{L}$ & $\mathrm{L}$ & $\mathrm{L}$ & $\mathrm{L}$ & $\bar{L}$ & $\mathrm{~L}$ & \\
\hline Mummaneni et $\mathrm{al}^{52}$ & $\mathrm{~L}$ & $\mathrm{~L}$ & $\mathrm{~L}$ & $\mathrm{~L}$ & $\mathrm{~L}$ & $\mathrm{~L}$ & $\mathrm{H}$ & $\mathrm{C} 1$ \\
\hline Nakagawa et al ${ }^{46}$ & $\mathrm{H}$ & $\mathrm{L}$ & $\mathrm{L}$ & $\mathrm{L}$ & $\mathrm{L}$ & $\mathrm{L}$ & $\mathrm{L}$ & \\
\hline Nakase et $\mathrm{al}^{47}$ & $\mathrm{H}$ & $\mathrm{L}$ & $\bar{L}$ & $\mathrm{~L}$ & $\mathrm{~L}$ & $\mathrm{~L}$ & $\mathrm{~L}$ & \\
\hline Nomura and Yoshida ${ }^{53}$ & $\mathrm{~L}$ & $\mathrm{~L}$ & $\mathrm{~L}$ & $\mathrm{~L}$ & $\mathrm{~L}$ & $\mathrm{~L}$ & $\mathrm{~L}$ & \\
\hline Onen et $\mathrm{al}^{54}$ & $?$ & $\mathrm{H}$ & $\mathrm{H}$ & $\mathrm{H}$ & $\mathrm{H}$ & $\mathrm{L}$ & $\mathrm{L}$ & $\mathrm{C} 3$ \\
\hline Orpen, 2010 & $\mathrm{~L}$ & $\mathrm{~L}$ & $\mathrm{~L}$ & $\mathrm{~L}$ & $\mathrm{~L}$ & $\mathrm{~L}$ & $\mathrm{~L}$ & \\
\hline Pakzaban $^{48}$ & $\mathrm{H}$ & $\mathrm{H}$ & $\mathrm{H}$ & $\mathrm{H}$ & $\mathrm{L}$ & $\mathrm{L}$ & $\mathrm{L}$ & \\
\hline Parker et $\mathrm{al}^{49}$ & $?$ & $\mathrm{H}$ & $\mathrm{H}$ & $\mathrm{H}$ & $\mathrm{L}$ & $\mathrm{L}$ & $\mathrm{H}$ & $\mathrm{C} 2$ \\
\hline Siddiqui and Yonemura ${ }^{56}$ & $\mathrm{~L}$ & $\mathrm{~L}$ & $\mathrm{~L}$ & $\mathrm{~L}$ & $\mathrm{~L}$ & $\mathrm{~L}$ & $\mathrm{~L}$ & \\
\hline Sunder and Prasad ${ }^{57}$ & $\mathrm{~L}$ & $\mathrm{~L}$ & $\mathrm{~L}$ & $\mathrm{~L}$ & $\mathrm{~L}$ & $\mathrm{~L}$ & $\mathrm{~L}$ & \\
\hline Velho et $\mathrm{al}^{58}$ & $\mathrm{H}$ & $\mathrm{H}$ & $\mathrm{H}$ & $\mathrm{H}$ & $\mathrm{L}$ & $\mathrm{L}$ & $\mathrm{L}$ & \\
\hline
\end{tabular}

Abbreviations: ?, unclear risk of bias; $\mathrm{H}$, high risk of bias; $\mathrm{L}$, low risk of bias; $\mathrm{C} 1$, the tear occurred during bone removal, the exact device not specified; C2, newly used device or system, tear incidence may be affected by the learning curve; C3, one arm was omitted from the analysis since tear causes were not specified. 


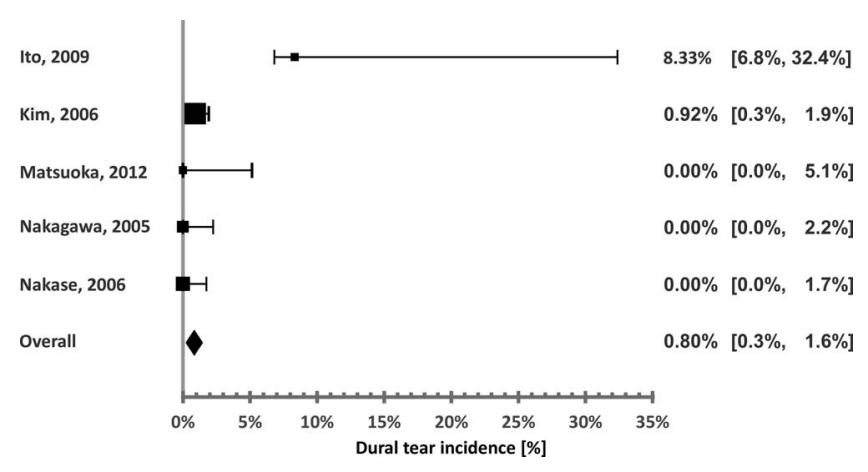

Figure 5. Sonopet Ultrasonic Aspirator durotomy incidence distribution.

geneity $\left(I^{2}=0 \%\right)$. The overall pooled incidence is $0.8 \%$.

Table 5 shows the statistical significance of the hypotheses that each set of 2 device groups is statistically different based on the calculated confidence intervals. As the results show, the SUA and DDS are safer than the HSD and the UBS at a statistically significant level. The difference between the DDS and the SUA is not statistically significant, as well as the difference between the HSD and the UBS.

\section{DISCUSSION}

The reference range of durotomy calculated using the administrative databases was $2.8-3.5 \%$. This range is in accordance with some of the literature studies, reporting low incidences, and lower than some of the relatively smaller-scale studies. A possible explanation for the lower incidence may be that, in smaller studies, a coincidental increase in the number of durotomy cases will cause a large deviation in the calculated incidence. In addition, as mentioned, the incidence is also affected by the surgeon experience, the procedure performed, and other parameters, and therefore, for specific scenarios, it may be higher (or lower) than the general incidence range.

The calculated durotomy incidences associated with the specific devices can assist physicians in determining their relative safety and selecting the most suitable device for the procedure. It is reasonable to expect that the incidence associated

Table 4. Subgroup heterogeneity assessment.

\begin{tabular}{lrc}
\hline & No. & $\boldsymbol{I}^{\mathbf{2}}$ \\
\hline High-speed drill + bone punch/Kerrison Ronguer & 14 & $11.4 \%$ \\
Ultrasonic BoneScalpel & 8 & $0 \%$ \\
Sonopet Ultrasonic Aspirator & 5 & $0 \%$ \\
\hline
\end{tabular}

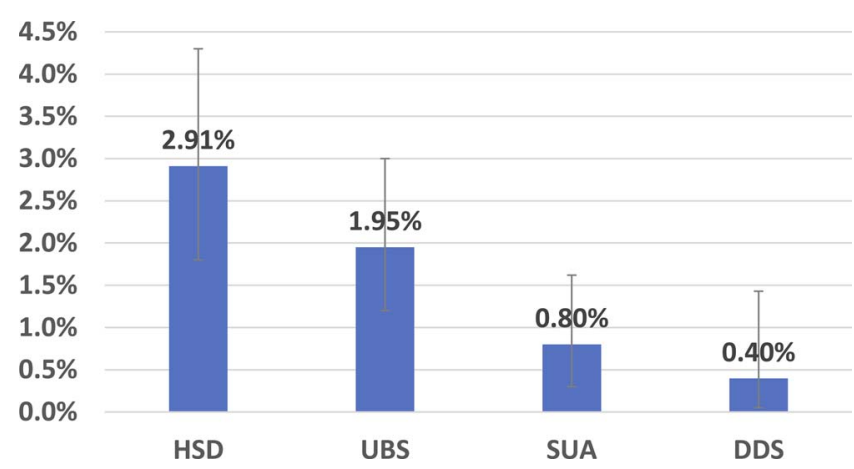

Figure 6. Durotomy incidence of all devices. The error bars represent the $95 \%$ confidence intervals. Abbreviations: HSD, high-speed drills; UBS, ultrasonic BoneScalpel; SUA, Sonopet Ultrasonic Aspirator; DDS, DReal Decompression System.

with a specific device would be lower than the general incidence, since there are additional causes for tears contributing to this rate. The incidences calculated for the 4 devices were $0.4-2.91 \%$. The calculated incidence for the HSD (along with the $\mathrm{KR}$ and $\mathrm{BP}$ ) is higher than the incidences calculated for the other devices. Since these devices were designed to improve the safety of surgical procedures, this result is reasonable. Three of the studied devices (the UBS, SUA, and DDS) are not commonly used, and therefore, it is reasonable to assume that the HSD was used for the vast majority of the procedures reported in the databases. However, the incidence associated with the HSD and $\mathrm{KR} / \mathrm{BP}, 2.91 \%$, is very similar to the calculated incidences using the databases, suggesting a possible inconsistency, since there are many other possible causes for tears, such as the use of dissectors, nerve root retractors, and other devices, especially in the presence of dural adhesions. Some of the studies included in this review report an overall incidence that was $55-100 \%$ higher than the combined HSD + $\mathrm{KR} / \mathrm{BP}$ incidence. ${ }^{40,51,60}$

This discrepancy can be a result of several factors. As mentioned, underreporting is suspected and may unrealistically lower the database results. As administrative databases are known to suffer from underreporting in other fields, it is reasonable to assume that dural tears would be underreported as well. Dural tears usually do not increase the facility's reimbursement, and consequently, surgeons may feel less inclined to mention them to the coder or even in the medical file. It is reasonable that simple tears, fixed immediately during the operation, which do not lead to subsequent complications or procedures and longer hospitalizations, would be less reported. For example, an analysis 
Table 5. Statistical significance of device group independence.

\begin{tabular}{lccc}
\hline & $\begin{array}{c}\text { Ultrasonic } \\
\text { BoneScalpel }\end{array}$ & $\begin{array}{c}\text { Sonopet Ultrasonic } \\
\text { Aspirator }\end{array}$ & $\begin{array}{c}\text { DReal Decompression } \\
\text { System }\end{array}$ \\
\hline High-speed drill + Kerrison Ronguer/bone press & 0.225 & $P<.01$ & $P<.01$ \\
Ultrasonic Bone Scalpel. & & $P<.01$ & $P<.01$ \\
Sonopet Ultrasonic Aspirator & & & 0.4233 \\
\hline
\end{tabular}

conducted on the Scoliosis Research Society database, ${ }^{14}$ based on reports by surgeons, reported a $1.6 \%$ durotomy incidence, which is low compared with the rates extracted for the other databases and the device-related incidences, suggesting that this database is more prone to underreporting.

This is a problem when trying to assess the overall safety of a device, procedure, or facility. The reliability of these reports should be improved if these databases are used for complication incidence analysis or to assess the complication rates of a specific procedure or in a certain facility. Since many studies rely on these databases, assessing the cost and risk of various surgical aspects, authors should be aware of the suspected underreporting and use these data with caution.

This study attempted to overcome this problem by excluding studies that are more prone to such omissions (not tear oriented or safety oriented, retrospective, etc). This approach could lead to another type of bias, considered here to be less significant. Future large-scale controlled studies are required to perform a more accurate and reliable analysis.

The relative share of durotomies diagnosed and coded during the procedure was approximately $84 \%$, suggesting possible late diagnosis or a need for additional medical care in almost $20 \%$ of the tears. When considering all the coded dural tears, the calculated incidence was approximately 3.5\%, which is more reasonable when compared with the $2.91 \%$ incidence associated with the HSD. Future studies should examine whether the added hospitalizations are the result of previously undiagnosed tears or readmissions following previously diagnosed and treated tears.

It is reasonable to assume that the specific devices' incidences are affected by the same parameters affecting the general incidence, and therefore, the validity of the incidence estimation of each device can be improved by expanding the available data and varying these parameters. For example, increasing the number of patients, procedures, surgeons, and institutions should increase the statistical significance of these findings.
This comparison is based on different publications which are clinically heterogenic due to varying diagnoses, procedures, and number of operated levels. However, ideally, durotomy incidence and device safety comparison should be conducted under the same conditions in order to draw more accurate and specific conclusions. Furthermore, it would also be beneficial to compare the overall durotomy incidence while using each device and not just the incidence of tears directly associated with the device. Unfortunately, these data were unavailable in some of the reported studies.

Procedure type obviously affects the risk of dural tears. Some procedures are more prone to tears, while others are safer due to requiring less bone removal or due to easier access and visibility. Ideally, this analysis should compare the risk for similar procedure types. Unfortunately, the available literature seems to be insufficient for an accurate comparison. Although some studies focus on a specific procedure type or spinal region, others include a variety of procedures. The procedures in which the tears occurred are not always specified, and therefore, these studies cannot be used for a specific comparison. As a result, the available number of studies that could be used for each procedure type would be very limited. The databases can theoretically be used for similar analysis, but the risk of underreporting affects the reliability of these results. For example, there is a large difference between the spinal fusion durotomy incidence between both databases ( 4.7 versus $2.1 \%$ ). There are also differences between studies focusing on similar procedures and the corresponding database incidences. For example, the NIS data suggest that cervical procedures are very safe $(0.4 \%)$, while some of the studies in this analysis that focus on cervical procedures report on a much higher incidence. These differences may be related to the skill level of a specific surgeon conducting the published study, the exact nature of the cervical procedure, the complexity of the cases presented in the article, and the smaller sample sizes of the publications, compared with the larger databases, as well as to the inherent problematic nature of the databases. 
Further studies on a larger population are required before analysis by procedure type could be accurately performed.

Another source of heterogeneity is the different use of the devices among surgeons and in different procedures. The extent of the use of the HSD, or the drill tip choice, may be completely different in 2 studies, affecting the overall risk of use.

Including the KR and BP in the HSD group and not in the other groups may cause some bias, increasing the HSD tear incidence. For example, as Table 2 shows, 1 of the studies in which the UBS was used reported 3 tears caused by the KR/BP. As mentioned, this inclusion is based on the required heavy use of KR/BP when the HSD is used, which is reduced when the safer devices are used. Ideally, the overall tear incidence for each device group should be compared as well, and the KR/BP contribution to the other groups should have been calculated. However, these data are missing from several of the studies discussed here, affecting the possibility and accuracy of such analysis. Another factor that may affect the results is the use patterns of the HSD when the alternative devices are used. For example, the SUA may still require some use of the HSD as well, since using the SUA to remove large amounts of bone is time consuming. ${ }^{27,47}$ The use of the HSD is specifically mentioned in some of the SUA studies analyzed here. ${ }^{44,47}$

Therefore, due to both reasons, future studies should also examine the tear contribution and use patterns of the HSD and KR/BP when the safer devices are used.

The studies in this analysis describing UBS, SUA, and DDS results have another inherent risk of bias, since these are all new devices, which are not commonly used. Therefore, it is not unreasonable to assume surgeons are not selecting the patients randomly for these experiments. The surgeon may prefer to use the new device during less complicated procedures or, alternatively, use it to improve the safety of potentially high-risk procedures. In addition, every new device has a learning curve. Two studies describing the UBS results report on a higher incidence in the first part of the study, which could be coincidental or related to this learning. Conducting controlled studies on a larger group of patients and after an initial period in which the surgeon is familiarized with the device would reduce the risk of this bias.

\section{CONCLUSIONS}

Incidental durotomy is a known complication of spine surgery and serves as a marker of safety in the evaluation of surgical alternatives. Administrative databases are a potentially useful tool for complication incidence analysis due to their size and diversity. In this study, several estimation methods were applied on different databases, and an overall durotomy incidence range of $2.8-3.5 \%$ was suggested. Since bone-removal devices are just one of the possible causes of dural tears, the general incidence is expected to be higher than the incidence associated with the devices, yet even the maximal estimation, $3.5 \%$, was only slightly higher than the incidence for the commonly used HSD, suggesting that these databases suffer from underrepresentation of this complication. This suspicion also arises due to the higher incidences reported in the literature. The results also suggest that the DDS and SUA offer a potentially safer alternative to traditional techniques used in spinal surgery, potentially reducing dural tear incidence by nearly $2.5 \%$.

\section{REFERENCES}

1. Ruban D, O'Toole JE. Management of incidental durotomy in minimally invasive spine surgery. Neurosurg Focus. 2011;31(4):E15.

2. Saxler G, Krämer J, Barden B, Kurt A, Pförtner J, Bernsmann K. The long-term clinical sequelae of incidental durotomy in lumbar disc surgery. Spine (Phila Pa 1976). 2005;30(20):2298-2302.

3. Guerin P, El Fegoun AB, Obeid I, et al. Incidental durotomy during spine surgery: incidence, management and complications. A retrospective review. Injury. 2012;43(4):397401.

4. Buck JS, Yoon ST. The incidence of durotomy and its clinical and economic impact in primary, short-segment lumbar fusion: an analysis of 17232 cases. Spine (Phila Pa 1976). 2015;40(18):1444-1450.

5. Nandyala SV, Elboghdady IM, Marquez-Lara A, Noureldin MN, Sankaranarayanan S, Singh K. Cost analysis of incidental durotomy in spine surgery. Spine (Phila Pa 1976). 2014;39(17):E1042-E1051.

6. Cammisa FP Jr, Girardi FP, Sangani PK, Parvataneni HK, Cadag S, Sandhu HS. Incidental durotomy in spine surgery. Spine (Phila Pa 1976). 2000;25(20):2663-2667.

7. Goodkin R, Laska LL. Unintended "incidental" durotomy during surgery of the lumbar spine: medicolegal implications. Surg Neurol. 1995;43(1):4-14.

8. McMahon P, Dididze M, Levi AD. Incidental durotomy after spinal surgery: a prospective study in an academic institution: clinical article. J Neurosurg Spine. 2012;17(1):30-36.

9. Tafazal SI, Sell PJ. Incidental durotomy in lumbar spine 
surgery: incidence and management. Eur Spine J. 2005;14(3):287-290.

10. Takahashi $\mathrm{Y}$, Sato $\mathrm{T}$, Hyodo $\mathrm{H}$, et al. Incidental durotomy during lumbar spine surgery: risk factors and anatomic locations: clinical article. J Neurosurg Spine. 2013;18(2):165-169.

11. Takahata M, Ito M, Abumi K, Kotani Y, Sudo H, Minami A. Clinical results and complications of circumferential spinal cord decompression through a single posterior approach for thoracic myelopathy caused by ossification of posterior longitudinal ligament. Spine (Phila Pa 1976). 2008;33(11):1199-1208.

12. Sin AH, Caldito G, Smith D, Rashidi M, Willis B, Nanda A. Predictive factors for dural tear and cerebrospinal fluid leakage in patients undergoing lumbar surgery. $J$ Neurosurg Spine. 2006;5(3):224-227.

13. Wiese M, Krämer J, Bernsmann K, Willburger RE. The related outcome and complication rate in primary lumbar microscopic disc surgery depending on the surgeon's experience: comparative studies. Spine J. 2004;4(5):550-556.

14. Williams BJ, Sansur CA, Smith JS, et al. Incidence of unintended durotomy in spine surgery based on 108478 cases. Neurosurgery. 2011;68(1):117-124.

15. Yoshihara H, Yoneoka D. Incidental dural tear in spine surgery: analysis of a nationwide database. Eur Spine J. 2014;23(2):389-394.

16. Preen DB, Holman CDJ, Lawrence DM, Baynham NJ, Semmens JB. Hospital chart review provided more accurate comorbidity information than data from a general practitioner survey or an administrative database. $J$ Clin Epidemiol. 2004;57(12):1295-1304. https://doi.org/10.1016/j.jclinepi.2004. 03.016 .

17. Hawker GA, Coyte PC, Wright JG, Paul JE, Bombardier C. Accuracy of administrative data for assessing outcomes after knee replacement surgery. J Clin Epidemiol. 1997;50(3):265273. https://doi.org/10.1016/S0895-4356(96)00368-X.

18. Powell H, Lim LL, Heller RF. Accuracy of administrative data to assess comorbidity in patients with heart disease. An Australian perspective. J Clin Epidemiol. 2001;54(7):687693.

19. Best WR, Khuri SF, Phelan M, et al. Identifying patient preoperative risk factors and postoperative adverse events in administrative databases: results from the department of veterans affairs national surgical quality improvement program 1. J Am Coll Surg. 2002;194(3):257-266. https://doi.org/10. 1016/S1072-7515(01)01183-8.

20. Mack MJ, Herbert M, Prince S, Dewey TM, Magee MJ, Edgerton JR. Does reporting of coronary artery bypass grafting from administrative databases accurately reflect actual clinical outcomes? J Thorac Cardiovasc Surg. 2005;129(6):1309-1317. https://doi.org/10.1016/j.jtcvs.2004.10.036.

21. Romano PS, Chan BK, Schembri ME, Rainwater JA. Can administrative data be used to compare postoperative complication rates across hospitals? Med Care. 2002;40(10):856867.

22. Wynn A, Wise M, Wright MJ, et al. Accuracy of administrative and trauma registry databases. J Trauma Acute Care Surg. 2001;51(3):464-468.

23. Khazim R, Dannawi Z, Spacey K, et al. Incidence and treatment of delayed symptoms of CSF leak following lumbar spinal surgery. Eur Spine J. 2015;24(9):2069-2076.

24. Agency for Healthcare Research and Quality. Healthcare
Cost and Utilization Project (HCUP). National Inpatient Sample (NIS). http://www.hcup-us.ahrq.gov/nisoverview.jsp. Accessed June 22, 2016.

25. Centers for Disease Control and Prevention (CDC). National Center for Health Statistics. National Hospital Discharge Survey (NHDS). http://www.cdc.gov/nchs/nhds/in dex.htm. Accessed June 22, 2016.

26. Moher D, Liberati A, Tetzlaff J, Altman DG. Preferred reporting items for systematic reviews and meta-analyses: the PRISMA statement. Ann Intern Med. 2009;151(4):264-269.

27. Bydon M, Xu R, Papademetriou K, et al. Safety of spinal decompression using an ultrasonic bone curette compared with a high-speed drill: outcomes in 337 patients: clinical article. $J$ Neurosurg Spine. 2013;18(6):627-633.

28. Higgins JP, Altman DG, Gøtzsche PC, et al. The Cochrane Collaboration's tool for assessing risk of bias in randomised trials. BMJ. 2011;343:d5928.

29. Freeman MF, Tukey JW. Transformations related to the angular and the square root. Ann Math Stat. 1950:607-611.

30. Barendregt JJ, Doi SA, Lee YY, Norman RE, Vos T. Meta-analysis of prevalence. J Epidemiol Community Health. 2013:jech-2013.

31. Higgins J, Thompson SG. Quantifying heterogeneity in a meta-analysis. Stat Med. 2002;21(11):1539-1558.

32. Blyth CR, Still HA. Binomial confidence intervals. $J$ Am Stat Assoc. 1983;78(381):108-116.

33. JavaStat-Binomial and Poisson Confidence Intervals. http://statpages.info/confint.html. Accessed January 30, 2018.

34. Yoshihara H, Yoneoka D. Incidental dural tear in cervical spine surgery: analysis of a nationwide database. Clin Spine Surg. 2015;28(1):19. https://doi.org/10.1097/BSD.0000000000000071.

35. Yoshihara H, Yoneoka D. Incidental dural tear in lumbar spinal decompression and discectomy: analysis of a nationwide database. Arch Orthop Trauma Surg. 2013;133(11):1501-1508. https://doi.org/10.1007/s00402-013-1843-1.

36. Al-Mahfoudh R, Qattan E, Ellenbogen JR, Wilby M, Barrett C, Pigott T. Applications of the ultrasonic bone cutter in spinal surgery-our preliminary experience. $\mathrm{Br} J$ Neurosurg. 2014;28(1):56-60.

37. Choi W-S, Kim J-S, Ryu K-S, Hur J-W, Seong J-H. Minimally invasive transforaminal lumbar interbody fusion at L5S1 through a unilateral approach: technical feasibility and outcomes. BioMed Res Int. 2016;2016:2518394. https://doi.org/ $10.1155 / 2016 / 2518394$.

38. Dezawa A, Mikami H, Sairyo K. Percutaneous endoscopic translaminar approach for herniated nucleus pulposus in the hidden zone of the lumbar spine. Asian $J$ Endosc Surg. 2012;5(4):200-203. https://doi.org/10.1111/j.17585910.2012.00142.x.

39. Hazer DB, Yaşar B, Rosberg H-E, Akbaş A. Technical aspects on the use of ultrasonic bone shaver in spine surgery: experience in 307 patients. BioMed Res Int. 2016;2016:842530. https://doi.org/10.1155/2016/8428530.

40. Farooq G, Shaikh A, Aorangzeb A, Altaf S. Incidental dural tears during lumbar spine surgery: risk factors, location, incidence, complications, treatment and clinical outcome. Pak $J$ Surg. 2013;29(3):205-210.

41. Hu X, Ohnmeiss DD, Lieberman IH. Use of an ultrasonic osteotome device in spine surgery: experience from the first 128 patients. Eur Spine J. 2013;22(12):2845-2849.

42. Ito K, Ishizaka S, Sasaki T, et al. Safe and minimally 
invasive laminoplastic laminotomy using an ultrasonic bone curette for spinal surgery: technical note. Surg Neurol. 2009;72(5):470-475.

43. Kast E, Mohr K, Richter H-P, Börm W. Complications of transpedicular screw fixation in the cervical spine. Eur Spine J. 2006;15(3):327-334.

44. Kim K, Isu T, Matsumoto R, Isobe M, Kogure K. Surgical pitfalls of an ultrasonic bone curette (SONOPET) in spinal surgery. Oper Neurosurg. 2006;59(4 Suppl 2):ONS390ONS393.

45. Matsuoka H, Itoh Y, Numazawa S, et al. Recapping hemilaminoplasty for spinal surgical disorders using ultrasonic bone curette. Surg Neurol Int. 2012;3:70.

46. Nakagawa H, Kim S-D, Mizuno J, Ohara Y, Ito K. Technical advantages of an ultrasonic bone curette in spinal surgery. J Neurosurg Spine. 2005;2(4):431-435.

47. Nakase H, Matsuda R, Shin Y, Park Y-S, Sakaki T. The use of ultrasonic bone curettes in spinal surgery. Acta Neurochir (Wien). 2006;148(2):207-213.

48. Pakzaban P. Neurotechnics. 2014. http://neuro-technics. com/wp-content/uploads/2013/08/BS-1302_BoneScalpel_Ultra sonic_Bone_Dissector_Applications_in_Spine_Surgery_by_ Dr_Pakzabañ.pdf. Accessed June 22, $201 \overline{6}$.

49. Parker SL, Kretzer RM, Recinos PF, et al. Ultrasonic BoneScalpel for osteoplastic laminoplasty in the resection of intradural spinal pathology: case series and technical note. Oper Neurosurg. 2013;73(1 Suppl Operative):ons61-ons66.

50. Eldin M, Mohamed M, Eissa EM, Elmorsy HM. Safety and efficacy of mini open transforaminal lumbar interbody fusion. Korean J Spine. 2016;13(4):190-195.

51. Hiraizumi Y. Posterior endoscopic discectomy using as endoscopic lumbar discectomy system developed in Japan. In: State of the Art for Minimally Invasive Spine Surgery. Tokyo: Springer; 2005:117-130.

52. Mummaneni PV, Haid RW, Traynelis VC, et al. Posterior cervical fixation using a new polyaxial screw and rod system: technique and surgical results. Neurosurg Focus. 2002;12(1):1-5.

53. Nomura K, Yoshida M. Microendoscopic decompression surgery for lumbar spinal canal stenosis via the paramedian approach: preliminary results. Glob Spine $J$. 2012;02(02):087-094. https://doi.org/10.1055/s-0032-1319774.

54. Onen MR, Yuvruk E, Akay S, Naderi S. The reliability of the ultrasonic bone scalpel in cervical spondylotic myelopathy: a comparative study of 46 patients. World Neurosurg. 2015;84(6):1962-1967.

55. Orpen NM, Shetty RR, Marshall R. Micro-decompression for lumbar spinal stenosis: the early outcome using a modified surgical technique. Bone Jt J. 2010;92(4):550-554.

56. Siddiqui A, Yonemura KS. Posterior cervical microendoscopic diskectomy and laminoforaminotomy. In: Endoscopic Spine Surgery and Instrumentation: Percutaneous Procedures. New York: Thieme; 2005:66-73.
57. Sunder S, Prasad R. Minimal invasive surgerymicroscopic laminotomy for lumbar canal stenosis. Apollo Med. 2006;3(4):404-406.

58. Velho V, Kharosekar H, Jasmit S, Valsangkar S, Palande DA. Ultrasonic osteotome: a cutting edge technology, our experience in 96 patients. Indian J Neurosurg. 2014;03(03):150153. https://doi.org/10.4103/2277-9167.146829.

59. Lidar Z, Lifshutz J, Bhattacharjee S, Kurpad SN, Maiman DJ. Minimally invasive, extracavitary approach for thoracic disc herniation: technical report and preliminary results. Spine J. 2006;6(2):157-163.

60. Martín-Láez R, Martínez-Agüeros JÁ, Suárez-Fernández D, Montiaga-Núñez F, Vázquez-Barquero A. Complications of endoscopic microdiscectomy using the EASYGO! system: is there any difference with conventional discectomy during the learning-curve period? Acta Neurochir (Wien). 2012;154(6):1023-1032.

Disclosures and COl: Ms Horovitz is an employee, Dr Ashkenazy is a consultant and shareholder, and Dr. Guyer is a paid speaker for Carevature Medical, Ltd, Rehovot, Israel, a company involved in the manufacture of a device examined in this study. For the remaining authors, none were declared. No surgeon or institution received payment or other benefit for conducting the study. All patients gave their informed consent. The experimental protocol and informed consent were approved by the Institutional Review Board. Portions of this work were presented in poster form at the 2016 CNS Annual Meeting, Congress of Neurological Surgeons, San Diego, California, USA, September 24-28, 2016, and at the Cleveland Spine Review: Hands-On 2016, Cleveland Clinic, Ohio, USA, August 9-16, 2016.

Corresponding Author: Shaked Horovitz, Carevature Medical, Ltd, 27 Eli Hurvitz St., Rehovot, Israel 7608801. Phone/Fax: (972) 528538884; Email: michal@isc.co.il.

Published 31 August 2018

This manuscript is generously published free of charge by ISASS, the International Society for the Advancement of Spine Surgery. Copyright (c) 2018 ISASS. To see more or order reprints or permissions, see http://ijssurgery.com. 